\title{
PENGARUH WAKTU FERMENTASI TERHADAP KADAR BIOETANOL DARI KULIT JAGUNG MANIS (Zea mays saccharata)
}

\section{The Effect of Fermentation Time on the Level of Bioethanol from Sweet Corn (Zea mays Saccharata) Bark}

\author{
*Renni Agustina M, Ratman, dan Irwan Said \\ Pendidikan Kimia/FKIP - Universitas Tadulako, Palu - Indonesia 94118 \\ Received 14 September 2016, Revised 14 October 2016, Accepted 18 November 2016
}

\begin{abstract}
This study aimed to determine the effect of fermentation time on the level of bioethanol from sweet corn bark. Sweet corn bark is one of the agricultural wastes containing cellulose which can be converted to bioethanol through several stapes. The steps were sample preparation, delignification, bydrolysis, and fermentation. This study applied fermentation process on the sweet corn bark using yeast bread (saccharomyces cereviseae) with time variations i.e 2-8 days. The products of fermented ethanol increasedand reached the optimum at 6 days fermentation with the bioethanol level of 4.50, then decrease the ethanol content at day 7 and 8.
\end{abstract}

Keywords: Corn bark, fermentation time, bioethanol.

\section{Pendahuluan}

Bahan bakar minyak (BBM) merupakan kebutuhan yang sangat diperlukan bagi semua kalangan terutama pengguna kendaraan agar aktivitas berjalan dengan lancar.Kebutuhan energi selama ini hanya dihasilkan dari minyak bumi dan batu bara. Energi tersebut tidak selamanya dapat memenuhi seluruh kebutuhan manusia dalam jangka waktu yang lama. Hal ini karena kuantitas minyak bumi pada lapisan bumi terus menipis akibat dari eksploitasi terus-menerus dan sifatnya yang tidak mudah untuk diperbaharui(Simomara, 2008)

Alternatif terbaru sebagai pengganti minyak bumi yang dibutuhkan adalah bioetanol.Sumber utama pembuatan bioetanol yaitu bahan yang mengandung struktur gula sederhana yang dapat diubah menjadi etanol yang dalam beberapa dekade terakhir, menjadi salah satu obyek penelitian yang menarik untuk mengetahui potensi dari bahanbahan lignoselulosa dalam memproduksi etanol (Wiratmaja, dkk., 2011). Bahan baku bioetanol dapat berasal dari biomassa sumber pati (jagung, ubi kayu, sorgun, dan lain-lain), sumber gula (molasses, nira tebu, nira kelapa, dan nira dari berbagai tanaman lain), dan

\section{*Correspondence:}

Reni Agustina

Program Studi Pendidikan Kimia, Fakultas Keguruan dan

Ilmu Pendidikan, Universitas Tadulako

email: agustinarenni@yahoo.com

Published by Universitas Tadulako 2016 sumber selulosa (onggok, jerami padi, ampas tebu, tongkol jagung, dan lain-lain sebagainya) (Mulyono, dkk., 2011)

Kulit jagung sangat berpotensi untuk dijadikan sebagai sumber bioetanol,karena kandungan senyawa yaitu lignin 15,7\%, selulosa 36,81\%, dan hemiselulosa 27,01\% (Ningsih, 2012). Pemanfaatan kulit jagung sebagai bioetanol juga dapat dijadikan solusi alternatif untuk mengurangi permasalahan lingkungan khususnya di kota Palu. Hal ini karena kulit jagung tidak begitu dimanfaatkan secara maksimal oleh masyarakat, sehingga hanya dibuang pada tumpukan sampah yang akhirnya dapat mencemari lingkungan.

Fachry, dkk.,(2013)telah melakukan penelitian tentang pembuatan bietanol dari limbah tongkol jagung dengan variasi konsentrasi asam klorida dan waktu fermentasi. Proses pembuatan bioetanol terdiri dari pretreatment, hidrolisa, fermentasi, dan pemurnian. Pretreatment dilakukan dengan menambahkan $\mathrm{NaOH} 0,1 \mathrm{M}$ pada bubuk tongkol jagung, yang selanjutnya dihidrolisa dengan menggunakan larutan $\mathrm{HCl}$.Hasil penelitian menunjukkan semakin tinggi konsentrasi asam, maka akan semakin tinggi pula kadar etanol yang didapat.Ariyani dkk., (2013) juga meneliti tentang produksi bioetanol dari jerami padi (Oryza sativa L.) melalui beberapa tahap yaitu proses delignifikasi, proses hidrolisis, 
fermentasi, dan destilasi. Tahap hidrolisis menggunakan konsentrasi $\mathrm{HCl}$ yang bervariasi dan waktu fermentasi yang bevariasi. Jerami padi dihidrolisis dengan $\mathrm{HCl}$ pada konsentrasi (7, 14, 21 dan 28\%). Untuk menentukan kadar glukosa hasil hidrolisis dianalisis dengan spektrofotometer UV-Vis. Dari hasil analisis menggunakan spektrofotometer UV-Vis konsentrasi $\mathrm{HCl}$ yang paling optimum pada konsentrasi $21 \%$ dengan kadar glukosa sebesar 70,85 ppm. Hasil analisis kadar glukosa pada berbagai variasi konsentrasi $\mathrm{HCl}$ menggunakan spektrofotometer UV-Vis diperlihatkan pada Tabel 1.

Tabel 1. Kadar glukosa pada berbagai variasi konsentrasi $\mathrm{HCl}$ (Ariyani, dkk., 2013)

\begin{tabular}{lll}
\hline Konsentrasi $\mathrm{HCl}$ & Absorbansi & Kadar glukosa $(\mathrm{ppm})$ \\
\hline $7 \%$ & 0,123 & 57,25 \\
$14 \%$ & 0,128 & 59,70 \\
$21 \%$ & 0,151 & 70,85 \\
$28 \%$ & 0,119 & 55,30 \\
\hline
\end{tabular}

Tulisan ini bertujuan untuk menentukan pengaruh waktu terhadap kadar bioetanol dari kulit jagung manis dengan proses fermentasi.

\section{Metode}

Alat dan Bahan

Alat yang digunakan pada penelitian ini yaitu neraca analitik, erlenmeyer, gelas kimia, labu ukur, gelas ukur, pipet tetes, corong, penangas listrik, $\mathrm{pH}$ meter, batang pengaduk, aluminium foil, kertas saring, ayakan 40 mesh, magnet stirrer, oven, blender, pompa vakum, seperangkat alat evaporator, alkoholmeter, stopwatch, dan spektrofotometer UV-Vis (T80+PG Instruments). Sedangkan bahan yang digunakan yaitu kulit jagung, larutan HCl (Merck), ammonium sulfat (Merck), larutan $\mathrm{NaOH}$ (Merck), urea (Merck), ragi roti (saccharomyces cereviseae), anthrone (Merck), dan aquades.

\section{Tahap Pendahuluan}

Kulit jagung diambil di Pasar Inpres yang berada di Kota Palu, kemudian kulit jagung tersebut dipotong kasar menjadi bagianbagian yang lebih kecil sebanyak mungkin. Selanjutnyakulit jagung dicuci dengan air dan dikeringkan dengan bantuan sinar matahari sampai kering. Kulit jagung yang sudah kering dipotong-potong dengan ukuran $+1 \mathrm{~cm}$. Kulit jagung digiling dengan blender dan diayak dengan ayakan 40 mesh. Kulit jagung yang sudah dihaluskan dioven pada $60^{\circ} \mathrm{C}$ selama
4 jam. Selanjutnya diayak kembali dengan menggunakan ayakan 40 mesh sehingga diperoleh serbuk kulit jagung. Kemudian hasil ayakan ditimbang.

\section{Tahap Delignifikasi}

Sebanyak $100 \mathrm{~g}$ serbuk kulit jagung hasil pengayakan kemudian ditambahkan 1350 $\mathrm{mL}$ aquades dan $150 \mathrm{~mL} \mathrm{NaOH} \mathrm{2 \%} \mathrm{dalam}$ erlenmeyer. Campuran dipanaskan dan diaduk dengan stirrer selama 2,5 jam pada suhu $80^{\circ} \mathrm{C}$. Selanjutnya dipisahkan dengan cara menyaringnya dengan menggunakan kertas saring. Residu penyaringan dioven pada suhu $100^{\circ} \mathrm{C}$ selama 2 jam kemudian menimbang residu selulosa.

\section{Tahap Hidrolisis}

Padatan 50 gram ditambahkan dengan larutan $\mathrm{HCl} 21 \%$ sebanyak $500 \mathrm{~mL}$. Selanjutnya dimasukkan kedalam erlenmeyer dan dipanaskan pada suhu $100^{\circ} \mathrm{C}$ selama 2,5 jam. Filtrat hasil saringan kemudian dianalisis menggunakan spektrofotometer UV-Vis untuk mengetahui kadar glukosa.

\section{Tahap Fermentasi}

Filtrat hasil hidrolisis dimasukan ke dalam 7 buah erlenmeyer masing-masing sebanyak $50 \mathrm{~mL}$. Kemudian ditambahkan larutan $\mathrm{NaOH} 6 \mathrm{M}$ pada masing-masing erlenmeyer hingga $\mathrm{pH}$-nya menjadi 5. Masing-masing larutan sampel ditambahkan dengan 4,2 gram ammonium sulfat dan 4,2 gram urea. Selanjutnya dipasteurisasi pada suhu $80^{\circ} \mathrm{C}$ selama 15 menitlalu didinginkan. Kemudian ditambahkan dengan ragi roti (saccharomyces cereviseae) sebanyak 4,9 gram. Selanjutnya, masing-masing erlenmeyerdibungkus dengan aluminium foil kemudian didiamkan dengan variasi waktu 2-8 hari pada suhu ruang.

\section{Tahap Pemisahan}

Proses evaporasi dilakukan dengan memasukkan hasil fermentasi kedalam erlenmeyer dan dipasang pada rangkaian alat evaporator. Pada proses ini dilakukan pemanasan pada suhu $80^{\circ} \mathrm{C}$. Kemudian masingmasing larutan hasil evaporasi ditentukan kadarnya dengan menggunakan alkoholmeter.

\section{Hasil dan Pembahasan}

Kadar glukosa pada penelitian diperoleh yaitu $6,3 \%(\mathrm{v} / \mathrm{v})$, dan data hasil pengukuran kadar bioetanol berdasarkan lama waktu fermentasidiperlihatkan pada Tabel2. 
Tabel 2. Pengukuran kadar bioetanol berdasarkan lama waktu fermentasi

\begin{tabular}{ll}
\hline Lama Fermentasi (hari) & Kadar Bioetanol (\%) \\
\hline 2 & 1,50 \\
3 & 2,35 \\
4 & 2,90 \\
5 & 3,65 \\
6 & 4,50 \\
7 & 3,80 \\
8 & 2,90 \\
\hline
\end{tabular}

Kulit jagung merupakan salah satu limbah pertanian yang mengandung abu 6,04\%, lignin $15,7 \%$, selulosa $36,81 \%$, dan hemiselulosa 27,01\%(Ningsih, 2012). Selulosa yang ada di dalam kulit jagung diisolasi terlebih dahulu untuk menghilangkan kandungan lignin (delignifikasi), yang kemudian dilanjutkan dengan proses hidrolisis(Ningsih, 2012).Proses delignifikasi dilakukan untuk meningkatkan kemampuan area permukaan(porositas) selulosa sehingga dapatmeningkatkan konversi selulosa menjadi glukosa(gula fermentasi), selain itu tujuan delignifikasi lainnya yaitu untuk membuka struktur rapat dari bahan lignoselulosa agar air dan enzim selulosa dapat mencapai selulosa (Brown, 2003). Pada penelitian ini digunakan larutan $\mathrm{NaOH}$ untuk menghilangkan kandungan lignin yang terdapat pada kulit jagung. Proses delignifikasi menyebabkan sampel berubah warna dari hijau kekuningan menjadi coklat. Berikut ini reaksi proses delignifikasi ditunjukkan pada Gambar 1.

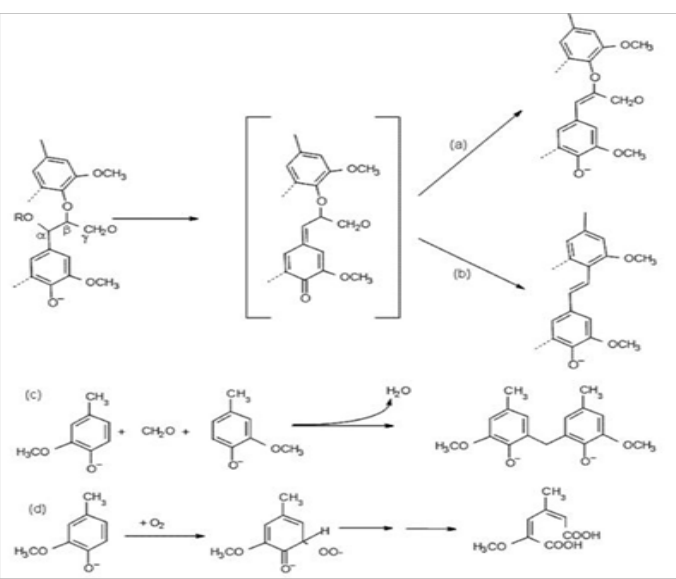

Gambar 1. Reaksi Delignifikasi(Cardona \& Sanchez, 2007)

Sampel kulit jagung dari hasil delignifikasi kemudian dihidrolisis menggunakan asam klorida untuk mendapatkan glukosa. Proses hidrolisis selulosa dapat dilakukan dengan beberapa metode, salah satunya dengan hidrolisis asam. Dalam proses hidrolisis ini gugus $\mathrm{H}^{+}$dari $\mathrm{HCl}$ akan mengubah serat dari kulit jagung menjadi suatu gugus radikal bebas. Sehingga gugus radikal bebas tersebut akan berikatan dengan gugus $\mathrm{OH}^{-}$dari molekul air dan menghasilkan glukosa(Hikmiyati \& Yanie, 2008). Berikut adalah reaksi hidrolisis selulosa :

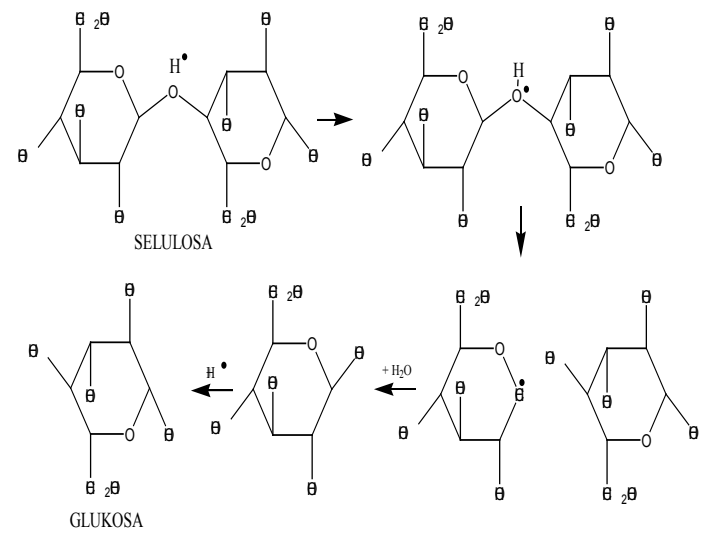

Gambar 2. Mekanisme Reaksi Hidrolisis

(Xiang, dkk., 2003)

Kadar glukosa dari filtrat hasil hidrolisis diukur dengan spektrofotometer UVVis menggunakan metode anthrone dan diperoleh $6,3 \%$ kadar glukosa.Hasil hidrolisis difermentasi menggunakan ragi roti (Saccharomyces cerevisiae) dengan variasi waktu selama 2 hari, 3 hari, 4 hari, 5 hari, 6 hari, 7 hari dan 8 hari. Saccharomyces cerevisiae merupakan khamir yang paling penting pada fermentasi, karena mampu memproduksi alkohol dengan konsentrasi tinggi dan fermentasi spontan (Soedarmadji, 1997). Mikroba Saccharomyces cerevisiae dapat mengkorversi gula menjadi etanol karena adanya enzim invertase dan enzim zimase yang dihasilkan oleh mikroba tersebut, dengan adanya kedua enzim tersebut mikroba Saccharomyces cerevisiae memiliki kemampuan untuk mengkonversi gula dari kelompok monosakarida maupun dari kelompok disakarida. Jika gula di dalam substrat adalah kelompok disakarida maka enzim invertase akan menghidrolisis disakarida menjadi monosakarida. Setelah itu, enzim zimase akan mengkonversi monosakarida tersebut menjadi alkohol dan karbondioksida (Judoamidjojo, dkk., 1992).

Proses fermentasi pada penelitian ini dilakukan pada $\mathrm{pH}$ 5.Hal ini sesuai dengan 
pendapat Azizah, dkk., (2012)bahwa kisaran pertumbuhan mikroba Saccharomyces cerevisiae yaitu $\mathrm{pH}$ 3,5-6,5 dan pada $\mathrm{pH}$ 4,5 adalah kondisi $\mathrm{pH}$ yang maksimal dapat dicapai. Jika pada kondisi basa mikroba tersebut tidak dapat tumbuh.Mikroba Saccharomyces cerevisiae akan tumbuh optimal dalam kisaran suhu 30$35^{\circ} \mathrm{C}$ dan puncak produksi alkohol dicapai pada suhu $33^{\circ} \mathrm{C}$ (Azizah, dkk., 2012). Hal ini menunjukan bahwa apabila pada suhu yang terlalu rendah, maka proses fermentasi akan berlangsung secara lambat. Sedangkan pada suhu yang terlalu tinggi menyebabkan mikroba Saccharomyces cerevisiae akan mati sehingga proses fermentasi tidak dapat berlangsung. Selain $\mathrm{pH}$ dan suhu, pemberian nutrisi juga mempegaruhi tumbuhnya Saccharomyces cerevisiae. Oleh karena itu pada penilitian ini dilakukan penambahan urea dan ammonium sulfat sebagai nutrisi untuk pertumbuhan Saccharomyces cerevisiae(Retno, dkk., 2009)

Hasil yang diperoleh pada waktu optimum fermentasi dari kulit jagung ditunjukkan pada Gambar 3.

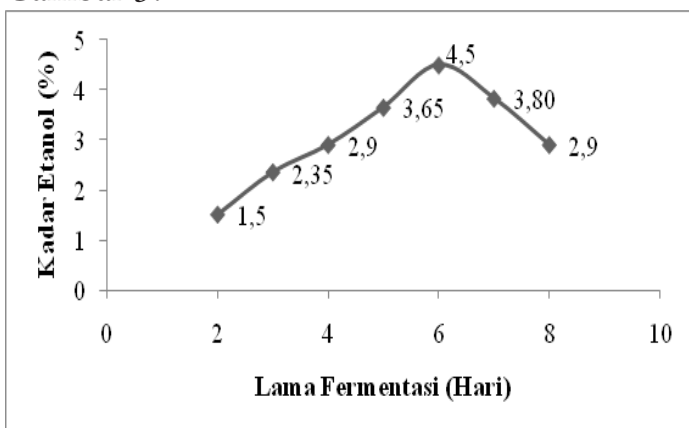

Gambar 3. Kurva hubungan antara lama waktu fermentasi terhadap kadar bioetanol yang dihasilkan.

Hasil Penelitian menunjukan bahwa kadar bioetanol terus mengalami kenaikan pada waktu fermentasi 2 hari hingga 6 hari namun pada hari ke-7 dan 8 kadar bioetanol yang diperoleh mangalami penurunan. Berdasarkan hasil yang diperoleh diketahui bahwa waktu fermentasi dari kulit jagung mencapai titik optimum pada waktu fermentasi selama 6 hari dengan kadar boetanol sebesar 4,50\%. Hal ini berartipertumbuhan ragi pada waktu tersebut beradapada fase eksponensial yaitu faseperkembangan ragi yang meningkat sehinggaragi bekerja secara optimum untuk mengubahglukosa menjadi etanol. Selain itu, penurunan kadar glukosa pada waktu fermentasi selama 7 dan 8 hari disebabkan karena jumlah mikroba semakin menurundan akan menuju ke fase kematian karenabioetanol yang dihasilkan semakin banyak dannutrien yang ada semakin menipis, selain itubioetanol yang dihasilkan telah teroksidasi lebihlanjut menjadi asam karboksilat(Noviani, dkk., 2014)

\section{Kesimpulan}

Waktu fermentasi sangat berpengaruh terhadap bioetanol yang dihasilkan. Pada penelitian ini, kadar bioetanol mengalami kenaikan dan mencapai kondisi optimum pada hari ke-6 yaitu 4,50\%, kemudian hari ke-7 dan 8 mengalami penurunan kadar etanol.

\section{Ucapan Terima Kasih}

Ucapan terima kasih penulis berikan kepada laboran Laboratorium Agroteknologi Fakultas Pertanian Universitas Tadulako yang banyak membantu penulis dalam menyelesaikan penelitian ini.

\section{Referensi}

Ariyani, E., Kusumo, E. \& Supartono. (2013). Produksi bioetanol dari jerami padi (oryza sativa L). Jurnal Institut Teknologi Nasional, 2(2), 168-172.

Azizah, N., Al-Baarri, A. N. \& Mulyani, S. (2012). Pengaruh lama fermentasi terhadap kadar alkohol, $\mathrm{pH}$, dan produksi gas pada proses fermentasi bioetanol dari whey substitusi kulit nanas. Jurnal Aplikasi Teknologi Pangan, 1(2), 72-77.

Brown, R. C. (2003). Biorenewable resources. New York: Blackwell Publishing Corp.

Cardona, A. \& Sanchez, O. J. (2007). Fuel ethanol production. Process design trends and integration opportunities. Bioresource Technology. 98(12), 45-57.

Fachry, A. R., Astuti, P. \& Puspitasari, T. G. (2013). Pembuatan bietanol dari limbah tongkol jagung dengan variasi konsentrasi asam klorida dan waktu fermentasi. Jurnal Teknik Kimia, 19(1), 60-69. 
Hikmiyati, N. \&Yanie, N.S. (2008). Pembuatan bioetanol dari limbah kulit singkong melalui proses hidrolisa asam dan enzimatis. Tugas Akhir Fakultas Teknik, Jurusan Teknik Kimia Universitas Diponegoro, Semarang.

Judoamidjojo, M., Darwin, A. A. \& Sa’id, E. G. (1992). Teknologi fermentasi. Jakarta: Rajawali Pers.

Mulyono, A. M. W., Handayani, C. B., Tari, A. I. N. \& Zuprizal. (2011). Fermentasi etanol dari jerami padi. Prosiding Seminar Hasil Penelitian dan Pengabdian Masyarakat, Universitas Veteran Bangun Nusantara, Sukoharjo.

Ningsih, E. R. (2012). Uji kinerja digester pada proses pulping kulit jagung dengan variabel subu dan waktu pemasakan. Tugas Akhir Fakultas Teknik, Program Studi Diploma III Teknik Kimia Universitas Diponegoro, Semarang.

Noviani, H., Supartono \& Siadi, K. (2014). Pengolahan limbah serbuk gergaji kayu sengon laut menjadi bioetanol menggunakan saccharomyces cerevisiae. Indonesian Journal of Chemical Science, 3(2), 147-151.

Retno, E. D., Kriswiyanti, E. A. \& Nur, A. (2009). Bioetanol fuel grade dari talas (colocasia esculenta). Jurnal Ekuilibrium, 8(1), 1-6.

Simomara, S. (2008). Membuat biogas pengganti bahan bakar minyak dan gas. Jakarta: Agromedia.

Soedarmadji. (1997). Prosedur analisa untuk bahan makanan dan pertanian. Yogyakarta: Liberty.

Wiratmaja, I. G., Kusuma, I. G. B. W. \& Winaya, I. N. S. (2011). Pembuatan etanol generasi kedua dengan memanfaatkan limbah rumput laut eucheuma cottonii sebagai bahan baku. Jurnal Ilmiah Teknik Mesin, 5(1), 75-84.

Xiang, Q.Lee, Y. Y., P.O. Pettersson \& Torget, R. W. (2003). Heterogeneous aspects of acid hydrolysis of a cellulose. Jurnal Humana Press, 107(1), $505-514$. 